\title{
Prognostic Value of Cortisol in Patients with Acute Ischemic Stroke
}

\author{
Farhad Iranmanesh, ${ }^{1}$ Behnaz Sedighi, ${ }^{2}$ and Bentolhoda Ziaadini ${ }^{3,}{ }^{*}$ \\ ${ }^{1}$ Professor of Neurology, Stroke Fellowship, Neurology Research Center, Kerman University of Medical Sciences, Kerman, Iran \\ ${ }^{2}$ Associated Professor of Neurology, Neurology Research Center, Kerman University of Medical Sciences, Kerman, Iran \\ ${ }^{3}$ Assistant Professor Neurology, Neurology Research Center, Kerman University of Medical Sciences, Kerman, Iran \\ "Corresponding author: Bentolhoda Ziaadini, Assistant Professor Neurology, Neurology Research Center, Kerman University of Medical Sciences, Kerman, Iran. E-mail: \\ dr_mohsen_sys@yahoo.com
}

Received 2016 April 02; Revised 2016 July 03; Accepted 2017 February 08.

\begin{abstract}
Background: Activation of the hypothalamo-pituitary-adrenal axis has been shown in acute ischemic stroke. Some recent studies suggest that serum cortisol level may have prognostic value in patients with ischemic stroke. The aim of this study was to evaluate the prognostic value of cortisol in patients with acute ischemic stroke.

Methods: In this prospective observational study, 51 patients with acute ischemic stroke were evaluated. Cardioembolic and lacunar strokes were excluded. In the first 24 hours of admission, serum cortisol level, national institutes of health stroke scale (NIHSS), diabetes and hypertension were assessed to determine their value to predict mortality within 90 days. The results were analyzed using descriptive statistics, t-test, chi-square test and logistic regression.

Results: In this study, 26 patients (51\%) were female and the rest were male. Serum cortisol level was normal in 37 patients (72.5\%). 14 patients died (27.5\%) during the follow-up period. The mean serum cortisol level of dead patients were $33.48 \pm 15.14 \mu \mathrm{g} / \mathrm{dL}$ and for alive patients was $35.10 \pm 19.74$. This difference was not statistically significant. After statistical analysis using logistic regression, no significant correlation between serum cortisol level and mortality was seen.

Conclusions: Although ischemic stroke is associated with change in serum cortisol level but this change has no prognostic value.
\end{abstract}

Keywords: Cortisol, Stroke, Prognosis

\section{Background}

Stroke is considered to be the most common neurological disease, yet one of the main causes of death and disability. The disease is divided into two types as ischemic and hemorrhagic while ischemic type includes about twothirds of the cases [1]. Numerous clinical variables have been identified as potential predictors of stroke outcome. However, the need to identify better biomarkers as predictors of outcome in acute ischemic stroke still exists. Some recent studies have shown that, stroke is associated with changes in stress markers such as cortisol [2-4]. Cortisol, an important hormone in the hypothalamic-pituitary - adrenal axis, has important effects on the metabolism of glucose, protein and lipid [5]. Change in serum level of this hormone have been reported in patients with ischemic stroke and some studies suggested high levels of this hormone is independently associated with increase in ischemic lesion volume [5]. Also, some studies indicated that cortisol level in patients with ischemic stroke is associated with significantly increased mortality rate $[4,6$, 7]. Some studies reported a Correlation between cortisol level and post stroke physical and psychological disability [8-11]. Some studies have demonstrated that, this association was not limited to ischemic stroke and there is a relation between cortisol level, morbidity and mortality rates in patients with subarachnoid and intracerebral hemorrhage [12-14]. Despite above-mentioned studies, in a number of researches, no association was found between cortisol level and mortality in ischemic stroke patients $[3,15,16]$. According to these controversies and lack of a final conclusion [17], this study aimed to evaluate serum cortisol level and its prognostic value in patients with acute ischemic stroke.

\section{Methods}

This prospective observational study was conducted on 51 patients with acute ischemic stroke in Kerman. Patients suffered from ischemic stroke for the first time, and were hospitalized within first 12 hours of onset of symptoms. Diagnosis of ischemic stroke was based on CT-scan and MRI (DWI, T1, and T2) findings. A cardiologist visited all patients and the patients underwent transthoracic echocardiography and ECG monitoring for 24 hours. In the case of clinical suspicion, trans-esophageal echo was done and cardioembolic stroke were excluded. Lacunar infarctions are also excluded. The patients with any underlying diseases other than diabetes and hypertension were excluded from the study. We excluded patients with other causes of activation of hypothalamo-pituitary-adrenal axis 
(e.g., those with surgical procedures within the last 3 weeks or nosocomial infections), intracranial hemorrhage, malignancy, febrile disorders, acute or chronic inflammatory disease at study enrollment. Patients receiving immunosuppressive agents, all types of steroids, and psychotropic drugs were also excluded. Also patients with any laboratory abnormalities such as elevated ESR or low glucose level were excluded from our study [5]. In this study, those patients undergoing drug therapy or having systolic blood pressure higher than 140 or diastolic higher than 90 $\mathrm{mm} / \mathrm{Hg}$ were considered as having hypertension. Patients were also treated diabetic who were under drug therapy or had fasting blood glucose greater than $126 \mathrm{mg} / \mathrm{mL}$ or random blood sugar over $200 \mathrm{mg} / \mathrm{dL}$ with the symptoms of diabetes. Those who inhaled five cigarettes per day were regarded as smokers [18]. Serum cortisol level was measured at $8 \mathrm{AM}$ on the day after admission by radioimmunoassay method. Serum cortisol level higher than $25 \mu \mathrm{g} / \mathrm{dL}$ was considered abnormal [5]. For every patient, a questionnaire containing demographic information and NIHSS, (which is a criterion with maximum score of 44 for evaluation of clinical condition of patients with stroke) on admission was provided [5] and patients were divided into two groups on the basis of normal and abnormal cortisol levels. Then they were followed for three months and at the end of the third month, they were evaluated in terms of mortality and its relation to cortisol serum levels. Power of study was $80 \%$ and $\mathrm{P} \leq 0.05$ was considered statistically significant. Demographic information and other findings were analyzed using descriptive statistics, t-test, chi-square test and logistic regression. This study was approved by the ethics committee of Kerman University of medical sciences.

\section{Results}

In this study, 51 patients were evaluated. Table 1 shows baseline characteristics data of the patients. Serum cortisol level was normal in 37 patients (72.5\%) and abnormal in the others. 14 patients (27.5\%) died during follow-up period. Also, No significant difference was seen between NIHSS and cortisol level or mortality. The mean level of cortisol was $33.48 \pm 15.14 \mu \mathrm{g} / \mathrm{dL}$ in death and $35.10 \pm 19.74 \mu \mathrm{g} / \mathrm{dL}$ in live patients. This difference was not statistically significant. Furthermore, no significant correlation was seen between the normal and abnormal cortisol levels and mortality. Also, after statistical analysis using logistic regression, no significant correlation was seen between cortisol level and mortality.
Table 1. Baseline Characteristics Data of the Patients ${ }^{\mathrm{a}}$

\begin{tabular}{lc}
\hline Variables & Value \\
\hline Female & $26(51)$ \\
male & $49(25)$ \\
\hline Diabetes & $18(35.3)$ \\
\hline Hypertension & $35(68.8)$ \\
\hline Smoking & $3(7.1)$ \\
\hline Alive & $37(72.5)$ \\
\hline Mean NIHSS, (SD) & $20.18(4.51)$ \\
\hline Mean Serum cortisol level,(SD) & $33.92(16.34)$ \\
\hline
\end{tabular}

${ }^{\mathrm{a}}$ Value are expressed as N. (\%).

\section{Discussion}

Prognostic markers available during the acute phase of stroke aid clinical decision-making. This study aimed to evaluate the prognostic value of cortisol in patients with acute ischemic stroke. Our findings showed that no significant correlation existed between cortisol level of patients with ischemic stroke on admission and short term mortality. Logistic regression modeling was used for multivariate analysis and this result persisted even after adjustment for risk factors. This result was agreement with some previous studies. For example, Schwartz and his colleagues studied 22 patients with ischemic stroke and observed no relation between cortisol serum level and final outcome [19]. Theodoropulou et al. conducted a study in Greece on 17 patients with cerebral infarction and found no correlation between mortality and serum cortisol level [3]. In another study in Germany, Fassbenderet al. found no association between cortisol level and the severity of stroke in patients with ischemic stroke [15]. Another study in America also showed no relationship between cortisol and severity of aphasia [16]. Despite our research and aforementioned studies, some studies have shown that there were opposite effects. For example Slowik and colleagues in a casecontrol study showed that cortisol level is correlated with volume of infarction, more complications and a poor prognosis [9]. Ziet al., in a cohort study, observed that cortisol level is related to 90-day mortality rate [5] Markund et al., in a study on 88 patients with cerebral infarctions, observed that high level of cortisol is related to delirium and mortality [7]. Similar studies in Switzerland, America and Denmark also confirmed above findings $[6,8,20]$. Some researches show that cortisol level change is seen only in stroke, but not in TIA [21]. However, some other studies have not confirmed this finding [22]. In some investigations, cortisol level has been linked to the lack of anhe- 
Table 2. The Relationship Between Cortisol Level and Mortality ${ }^{\mathrm{a}}$

\begin{tabular}{lccc}
\hline Variables & Patient's Condition & Sum & PValue \\
\hline Cortisol level & Alive & Dead & \\
Normal & $29(78.4)$ & $8(57.1)$ & $37(72.5)$ \\
Abnormal & $8(21.6)$ & $6(42.9)$ & $14(27.5)$ \\
\hline
\end{tabular}

${ }^{\mathrm{a}}$ Value are expressed as N. \%(\%)

Table 3. The Relation Between Mortality and Variables

\begin{tabular}{|c|c|c|c|c|c|c|}
\hline \multirow[t]{2}{*}{ Variables } & \multicolumn{3}{|c|}{ Crud } & \multicolumn{3}{|c|}{ Adjusted } \\
\hline & P Value* & CI & OR & PValue* & CI & OR \\
\hline Cortisol level & 0.750 & $0.969-1.04$ & 1.006 & 0.183 & $0.980-1.11$ & 1.044 \\
\hline History of smoking & 0.999 & & 8.07 & 0.99 & & 1.32 \\
\hline History of hypertension & 0.791 & $0.216-3.21$ & 0.833 & 0.412 & $0.019-5.04$ & 0.312 \\
\hline History of diabetes & 0.05 & $0.077-1.002$ & 0.278 & 0.353 & $0.041-3.13$ & 0.358 \\
\hline Age & 0.341 & $0.972-1.08$ & 1.02 & 0.7 & $0.944-1.09$ & 1.04 \\
\hline Gender & 0.274 & $0.133-1.68$ & 0.472 & 0.969 & $0.211-10.24$ & 1.47 \\
\hline
\end{tabular}

donia and depression in patients with cerebral infarction which express the relation between cortisol level and some of psychological symptoms [11, 23]. Despite numerous studies in this field, disagreements on the effect of cortisol on the prognosis of stroke remain strong so that a systematic review which was published in 2014 showed that elevated cortisol after stroke is associated with dependency, morbidity, and mortality but, there is insufficient evidence to conclude that these relationships are independent of stroke severity [17]. Whether the increase in cortisol level is merely a result of the infarct severity or an independent factor, is still controversial. Some studies show that, increase in cortisol directly worsen ischemic damaged area, especially in the hippocampus. Also increase in cortisol is associated with ischemic heart disease events and reduced resistance to infections in patients with stroke so that these factors increase the mortality rate $[5,24]$. Some other studies indicated a correlation between cortisol and inflammatory markers such as fibrinogen, white blood cells, and the possible effects of cortisol on prognosis is more originated from inflammatory responses than stressinduced responses [9]. In our study, $27.5 \%$ of patients had increased levels of serum cortisol. Regardless of whether cortisol level affect prognosis or not, all studies have shown that acute stroke is associated with change in serum cortisol level. Frequency of Increased level of this hormone in different researches is reported from 24 to $38 \%$. Such discrepancies may be attributed to differences among these studies such as study sample sizes, population study, eval- uation method and time of measuring hormone level [5]. It should be noted that this increase was not only observed in the blood, but also in urine and saliva $[5,25]$. The etiology of increase cortisol level in ischemic stroke is not obvious and some studies claim that ischemic stroke acts like a stressor and activates pituitary - adrenal axis [5, 26]. This finding is also seen in intracerebral hemorrhage [14, 27]. Our study has several limitations, including a relatively short follow-up period and small sample size. Obviously, if the follow-up period becomes longer in future studies, the results will be more valuable. Our next limitation was single measurement of cortisol on the first day. Measuring the serial of cortisol levels may affect the results and should be considered in future studies.

In conclusion, our findings showed ischemic stroke is associated with change in serum cortisol level but this change has no prognostic value.

\section{Acknowledgments}

This article was extracted from a project (N: 94/649).The authors thank the neurology research center of Kerman University of Medical Sciences for supporting this project.

\section{Footnotes}

Conflict of interest: None declared. 
Funding/Support: Kerman University of Medical Sciences.

\section{References}

1. Prabhakaran S, Ruff I, Bernstein RA. Acute stroke intervention: a systematic review. JAMA. 2015;313(14):1451-62. doi: 10.1001/jama.2015.3058. [PubMed: 25871671].

2. Back C, Thiesen KL, Skovgaard K, Edvinsson L, Jensen LT, Larsen VA, et al. RAAS and stress markers in acute ischemic stroke: preliminary findings. Acta Neurol Scand. 2015;131(2):132-9. doi: 10.1111/ane.12298. [PubMed: 25214428].

3. Theodoropoulou A, Metallinos IC, Elloul J, Taleli P, Lekka N, Vagenakis AG, et al. Prolactin, cortisol secretion and thyroid function in patients with stroke of mild severity. Horm Metab Res. 2006;38(9):587-91. doi: 10.1055/s-2006-950505. [PubMed: 16981141].

4. Anne M, Juha K, Timo M, Mikko T, Olli V, Kyosti S, et al. Neurohormonal activation in ischemic stroke: effects of acute phase disturbances on long-term mortality. Curr Neurovasc Res. 2007;4(3):170-5. doi: 10.2174/156720207781387169. [PubMed: 17691970].

5. Zi WJ, Shuai J. Cortisol as a prognostic marker of short-term outcome in chinese patients with acute ischemic stroke. PLoS One. 2013;8(9):e72758. doi: 10.1371/journal.pone.0072758. [PubMed: 24069157].

6. Neidert S, Katan M, Schuetz P, Fluri F, Ernst A, Bingisser R, et al. Anterior pituitary axis hormones and outcome in acute ischaemic stroke. J Intern Med. 2011;269(4):420-32. doi: 10.1111/j.1365-2796.2010.02327.x. [PubMed: 21205022].

7. Marklund N, Peltonen M, Nilsson TK, Olsson T. Low and high circulating cortisol levels predict mortality and cognitive dysfunction early after stroke. J Intern Med. 2004;256(1):15-21. doi: 10.1111/j.13652796.2004.01334.x. [PubMed: 15189361].

8. Zierath D, Tanzi P, Cain K, Shibata D, Becker K. Plasma alphamelanocyte stimulating hormone predicts outcome in ischemic stroke. Stroke. 2011;42(12):3415-20. doi: 10.1161/STROKEAHA.111.627331. [PubMed: 21960572].

9. Slowik A, Turaj W, Pankiewicz J, Dziedzic T, Szermer P, Szczudlik A. Hypercortisolemia in acute stroke is related to the inflammatory response. J Neurol Sci. 2002;196(1-2):27-32. [PubMed: 11959152].

10. Olsson T, Marklund N, Gustafson Y, Nasman B. Abnormalities at different levels of the hypothalamic-pituitary-adrenocortical axis early after stroke. Stroke. 1992;23(11):1573-6. doi: 10.1161/01.STR.23.11.1573. [PubMed: 1332219].

11. Kwon OJ, Kim M, Lee HS, Sung KK, Lee S. The Cortisol Awakening Response in Patients with Poststroke Depression Is Blunted and Negatively Correlated with Depressive Mood. Biomed Res Int. 2015;2015:709230. doi: 10.1155/2015/709230. [PubMed: 26417598].

12. Zetterling M, Engstrom BE, Hallberg L, Hillered L, Enblad P, Karlsson $\mathrm{T}$, et al. Cortisol and adrenocorticotropic hormone dynamics in the acute phase of subarachnoid haemorrhage. $\mathrm{Br} J$ Neurosurg. 2011;25(6):684-92. doi: 10.3109/02688697.2011.584638. [PubMed: 22115015].

13. Huttner HB, Kiphuth IC, Teuber L, Lucking H, Kloska SP, Staykov D, et al. Neuroendocrine changes in patients with spontaneous supratentorial intracerebral hemorrhage. Neurocrit Care. 2013;18(1):39-44. doi: 10.1007/s12028-011-9622-8. [PubMed: 21837535]
14. Yang X, Ren W, Zu H, Dong Q. Evaluate the serum cortisol in patients with intracerebral hemorrhage. Clin Neurol Neurosurg. 2014;123:12730. doi: 10.1016/j.clineuro.2014.05.019. [PubMed: 25012024].

15. Fassbender K, Schmidt R, Mossner R, Daffertshofer M, Hennerici $M$. Pattern of activation of the hypothalamic-pituitary-adrenal axis in acute stroke. Relation to acute confusional state, extent of brain damage, and clinical outcome. Stroke. 1994;25(6):1105-8. doi 10.1161/01.STR.25.6.1105. [PubMed: 8202965].

16. Laures-Gore JS. Aphasia severity and salivary cortisol over time. J Clin Exp Neuropsychol. 2012;34(5):489-96. doi 10.1080/13803395.2012.658356. [PubMed: 22352852]

17. Barugh AJ, Gray P, Shenkin SD, MacLullich AM, Mead GE. Cortisol levels and the severity and outcomes of acute stroke: a systematic review. J Neurol. 2014;261(3):533-45. doi: 10.1007/s00415-013-7231-5. [PubMed: 24477489].

18. Iranmanesh F, Sheykholeslami NZ, Gadari F, Ahmady J. Acute ischemic non-embolic stroke and serum level of uric acid. Iran J Neurol 2012;11(1):1-5. [PubMed: 24250850].

19. Schwarz S, Schwab S, Klinga K, Maser-Gluth C, Bettendorf M. Neuroendocrine changes in patients with acute space occupying ischaemic stroke. J Neurol Neurosurg Psychiatry. 2003;74(6):725-7. doi: 10.1136/jnnp.74.6.725. [PubMed:12754339].

20. Christensen H, Boysen G, Johannesen HH. Serum-cortisol reflects severity and mortality in acute stroke. J Neurol Sci. 2004;217(2):175-80. [PubMed: 14706221].

21. Liesz A, Ruger H, Purrucker J, Zorn M, Dalpke A, Mohlenbruch M, et al. Stress mediators and immune dysfunction in patients with acute cerebrovascular diseases. PLoS One. 2013;8(9):e74839. doi:10.1371/journal.pone.0074839. [PubMed: 24069356].

22. Radak D, Resanovic I, Isenovic ER. Changes in hypothalamuspituitary-adrenal axis following transient ischemic attack. Angiology. 2014;65(8):723-32. doi: 10.1177/0003319713503487. [PubMed: 24065626].

23. Terroni L, Amaro EJ, Iosifescu DV, Mattos P, Yamamoto FI, Tinone G, et al. The association of post-stroke anhedonia with salivary cortisol levels and stroke lesion in hippocampal/parahippocampal region. Neuropsychiatr Dis Treat. 2015;11:233-42. doi:10.2147/NDT.S73722. [PubMed: 25678790].

24. Cieslak M, Wojtczak A, Cieslak M. Relationship between the induction of inflammatory processes and infectious diseases in patients with ischemic stroke. Acta Biochim Pol. 2013;60(3):345-9. [PubMed: 24046817].

25. Kumar D, Rasool R, Masoodi KZ, Bhat IA, Verma S, Saleem S. Strokeinduced immune depression-a randomized case control study in Kashmiri population of North India. J Stroke Cerebrovasc Dis 2014;23(8):2041-6. doi: 10.1016/j.jstrokecerebrovasdis.2014.03.002. [PubMed: 25113081].

26. Blum CA, Mueller C, Schuetz P, Fluri F, Trummler M, Mueller B, et al. Prognostic value of dehydroepiandrosterone-sulfate and other parameters of adrenal function in acute ischemic stroke. PLoS One. 2013;8(5):e63224. doi: 10.1371/journal.pone.0063224. [PubMed: 23650556].

27. Poll EM, Gilsbach JM, Hans FJ, Kreitschmann-Andermahr I. Blunted serum and enhanced salivary free cortisol concentrations in the chronic phase after aneurysmal subarachnoid haemorrhage-is stress the culprit?. Stress. 2013;16(2):153-62. doi: 10.3109/10253890.2012.697946. [PubMed: 22735076]. 